\title{
Comparing resistance to water flow between two spinal needles
}

\section{Tam Al-Ani, Queen Elizabeth University Hospital, Glasgow, UK}

\section{Background}

This study compares

resistance to water flow between Vygon

Whitacre ${ }^{\circledR} 25 \mathrm{G} \times 90 \mathrm{~mm}$ and Pajunk Sprotte®

NRFit $25 \mathrm{G} \times 90 \mathrm{~mm}$ spinal needles.
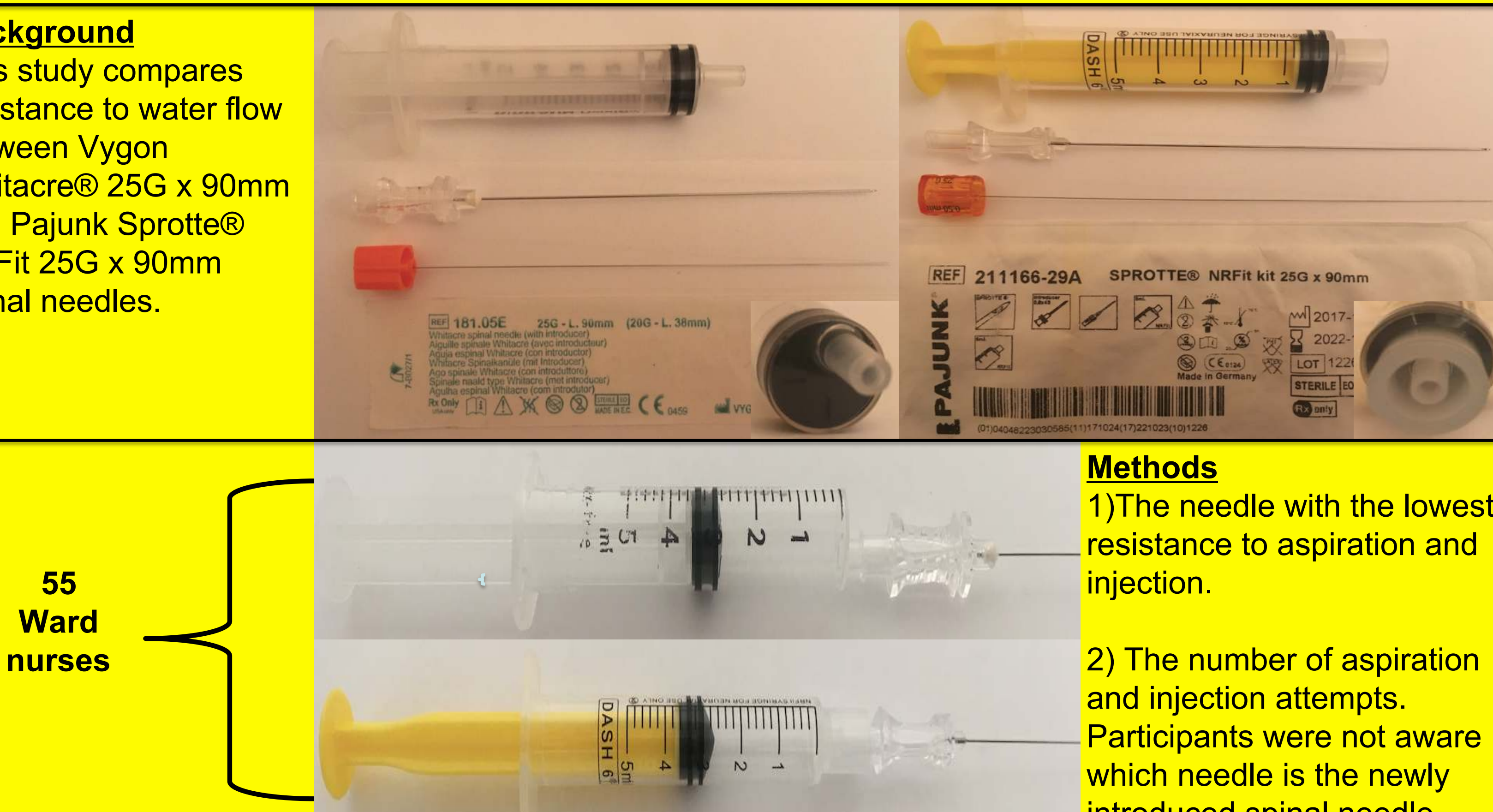

Methods

1)The needle with the lowest resistance to aspiration and injection.

2) The number of aspiration and injection attempts.

Participants were not aware which needle is the newly introduced spinal needle.

\section{Results}

The majority of participants felt that there was less resistance to aspiration and injection when using the Vygon Whitacre $®$ compared with the Pajunk Sprotte ${ }^{\circledR}$ NRFit needle.

The majority of participants were able to determine the difference in resistance in one attempt $(72 \%$ of participants for aspiration and $74 \%$ for injection). The maximum number of attempts was three.

\section{Figure1: Resistance to aspiration and injection}

\section{Lowest resistance to aspiration}

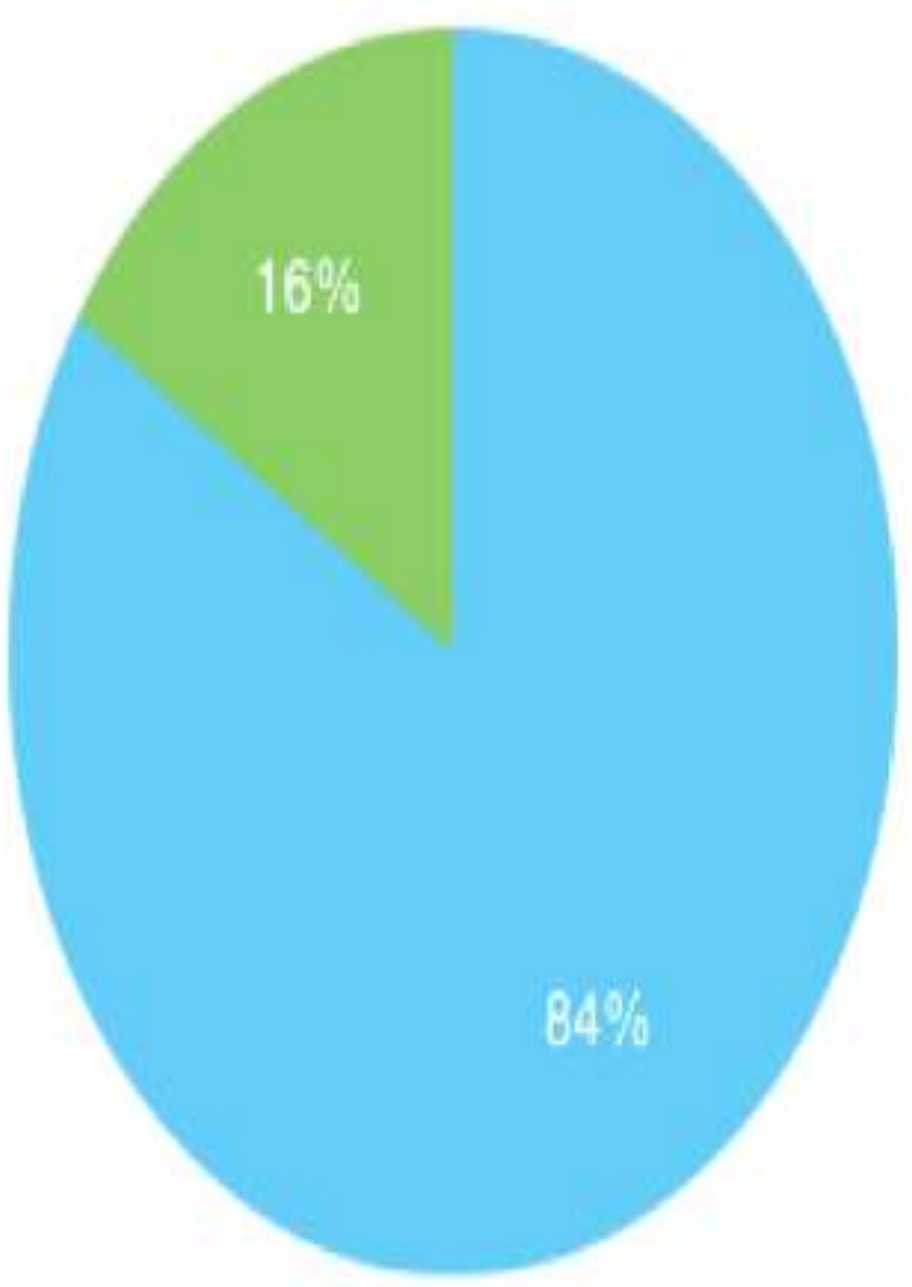

Lowest resistance to injection

Pajunk Sprotte@ NRFit

Vygon Whitacre@ No difference

\section{LUER}

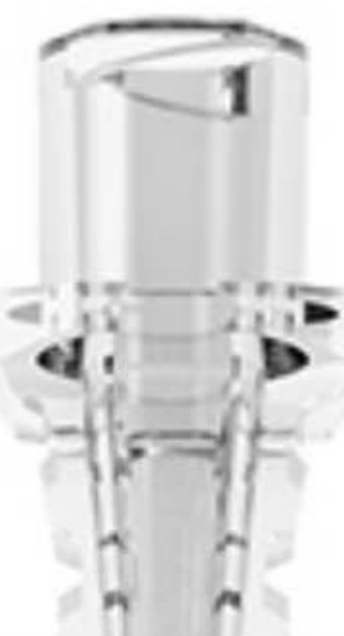

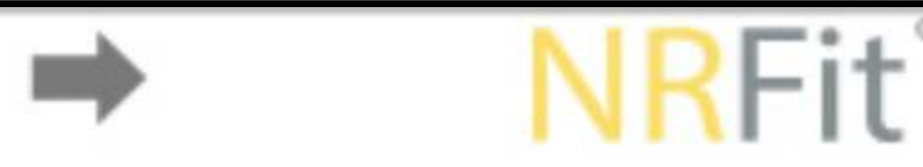

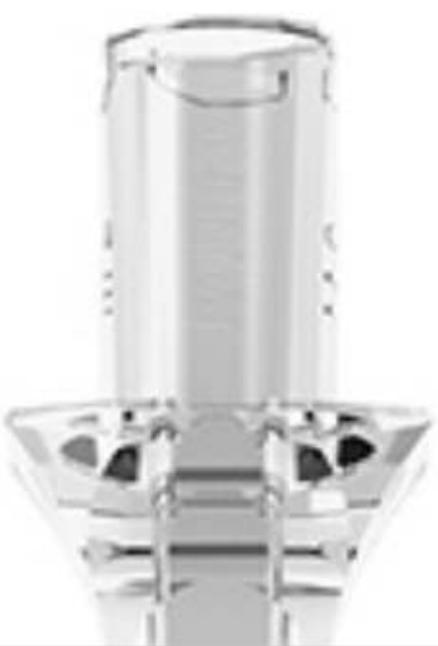

\section{Conclusions}

Practitioners who have switched to using the Pajunk Sprotte® NRFit 25Gx $90 \mathrm{~mm}$ from Vygon Whitacre $825 \mathrm{G} \times 90 \mathrm{~mm}$ spinal needle need to be aware of the higher resistance to flow on aspiration and injection. 